\title{
Sources of Information and Health Care Experiences Related to COVID-19 among Women Involved in Criminal Legal System in Three U.S. Cities
}

\author{
Lorvick $\mathrm{J}^{1 *}$, Hemberg $\mathrm{J}^{1}$, Cropsey $\mathrm{K}^{2}$, Wickliffe $\mathrm{J}^{3}$, Faust $\mathrm{A}^{2}$, Comfort $\mathrm{M}^{4}$ and Ramswamy $\mathrm{M}^{3}$ \\ ${ }^{1}$ Community Health and Implementation Research Program, RTI International, Berkeley CA, USA \\ ${ }^{2}$ Department of Psychiatry, University of Alabama, Birmingham AL, USA \\ ${ }^{3}$ Department of Population Health, University of Kansas School of Medicine, Kansas City KS, USA \\ ${ }^{4}$ Division for Applied Justice Research, RTI International, Berkeley CA, USA
}

*Corresponding author: Jennifer Lorvick, Community Health and Implementation Research Program, RTI International, Berkeley CA, USA; Email: jlorvick@rti.org

Received: September 2, 2020; Accepted: September 22, 2020; Published: October 8, 2020

\begin{abstract}
Women in the United States criminal legal (CL) system are at the nexus of several drivers of the COVID-19 pandemic, including incarceration, poverty, chronic illness and racism. There are 1.25 million women incarcerated or on community supervision (probation or parole) in the U.S. We present findings regarding the impact of COVID-19 on women in the CL system ( $\mathrm{N}=344)$ during the early days of the pandemic. Participants were drawn from community settings in an ongoing study of cervical cancer risk in three U.S. cities: Birmingham, Alabama, Oakland, California and Kansas City, which straddles the states of Kansas and Missouri. Regional differences were found in COVID-19 testing and perceived susceptibility to the virus, but not in COVIDrelated disruptions to health care. We found differences by race/ethnicity in trusted sources of information about COVID. Black women had higher odds of choosing TV as their most trusted source of information, while White women were more likely to cite government or social service agencies as their most trusted source. Notably, 15\% of women said they did not trust any source of information regarding COVID-19. COVID-19 disproportionately impacts populations with high levels of mistrust towards medical and government institutions, a result of the twin legacies of medical mistreatment and structural racism. Our findings underscore the need for innovative strategies to reach these groups with accurate and timely information.
\end{abstract}

Keywords: Health communication, COVID-19, Criminal justice, Racial disparities, Trust, Women

\section{Introduction}

As of 2017, there were 1.25 million women under control of the criminal legal (CL) system in the United States, including over 225,000 women in jails or prisons [1,2] and over a million women under community supervision (probation or parole) [3]. Women involved in the CL system live at the nexus of several drivers of the U.S. COVID-19 pandemic, including incarceration, poverty, chronic illness and racism [4]. They are predominantly low-income and disproportionately women of color [5]. They have markedly higher rates of underlying chronic health conditions, associated with poor COVID-19 outcomes, than women in the general population [6,7]. In addition, hundreds of thousands of women transition between community and carceral settings each year [8], and prisons and jails continue to be revealed as hotbeds of COVID-19 transmission [9]. Thus, COVID-19 is very much a pertinent risk for women who are involved in the CL system in the U.S [10].

In the U.S., the story of COVID-19 is one of distinct and marked racial/ethnic disparities, with Black and Hispanic/Latinx people afflicted by disproportionately high rates of infection [11-13] and death [14,15], In addition, the socioeconomic consequences of COVID-19, such as loss of employment and eviction from housing, disproportionately affect people of color [16,17] People of color are also overrepresented among those employed in jobs with high risk of exposure, such as home health aides, cashiers and meat packing workers [18]. Another central theme of the pandemic in the U.S. is the lack of a coordinated national response, leading to different policies and public health mandates in different regions of the country. The lack of a single authoritative source of guidance contributes to confusion and people relying on widely divergent sources of information about the virus. With this backdrop, we sought to understand how women with CL involvement were affected by COVID-19 early in the pandemic. Specifically, we examined how COVID-19 had affected their health care and what sources of information about the virus they relied on. The purpose was to determine whether there were regional or racial/ethnic differences in these outcomes, to help inform health care and communication efforts.

\section{Materials and Methods}

Research participants were enrolled in an ongoing, three-city study of cervical cancer risk among women involved in the CL system, funded by the National Cancer Institute (R01CA226838). Data are collected annually with a cohort of women in community settings 
in three U.S. cities: Kansas City (Midwest), Birmingham (South) and Oakland (West). In response to anecdotal evidence about challenges and disruptions created by the pandemic in the study population, we conducted a brief supplemental survey (5-10 mins) over eight weeks from mid-April to mid-June 2020. Interviews were conducted by telephone rather than in person due to shelter-in-place orders. Participants received a $\$ 20$ incentive for responding to the survey. Regular check-ins with participants was a routine part of the research protocol and was approved in accordance with the National Institutes of Health single institutional review board policy for multisite research.

\section{Measures}

The primary independent variables were race/ethnicity and study site (city). Participants were asked "How do you identify in terms of your race or ethnicity (select all that apply)?" and read a list of several different racial/ethnic groups. We used responses to create a three-level nominal categorical variable race variable. A majority of participants endorsed one race, predominantly Black or White. Small numbers of women reported more than one race $(n=10)$, Latinx only $(n=17)$, American Indian or Alaska Native $(n=1)$, or Asian or Pacific Islander $(n=4)$. We combined these women into a single category as "Other People of Color (POC)." While useful for analytic purposes, we do not draw conclusions about this group in our findings, as we would be generalizing from numerous racial/ethnic backgrounds. Site was determined by the city in which interviews were conducted. To assess health care utilization, participants were asked "Has a health care provider canceled or postponed any regular appointments due coronavirus?" and "Have any of your health care appointments been conducted by phone or video (Telemedicine) instead of in person, due to the coronavirus?" which were both coded yes vs. no. Perceived susceptibility to COVID-19 was assessed with an item which asked, "On a scale of 1-10, how likely do you think you are to get the coronavirus, with 1 being not at all likely and 10 being certain to get it?" Dependent variables related to sources of information about COVID-19. Participants were asked, "What are your sources of information about COVID-19? (select all that apply)" and read a list of potential sources. Each source was dichotomized yes vs. no. To determine most trusted source of information, participants were asked a follow-up question, "Which single source do you trust the most?" Rather than use a multilevel variable, we dichotomized these responses (most trusted $\mathrm{y} / \mathrm{n}$ ) for a more precise examination of associations.

\section{Data Analysis}

Descriptive statistics were conducted for all study variables. Logistic regressions were used to determine the unadjusted odds ratios (ORs) and 95\% confidence intervals (CIs) for the associations between outcomes and race. Adjusted ORs and $95 \%$ CIs for the associations between outcomes and race were examined controlling for study site, age, and other relevant factors (depending on the model). Analyses were run in STATA Version 16.1 (Stata Corp., College Station, TX, USA).

\section{Results}

We successfully reached $73 \%$ of the study cohort by telephone during the data collection period, for a sample of 344 women (Table 1). Race/ethnicity varied by site, with more White women in Kansas City and Birmingham. Mean age also varied by site, with a mean of 39 years in Kansas City, 40 in Birmingham and 46 in Oakland. All women had histories of criminal legal involvement, most having experienced both incarceration and community supervision (probation or parole). Women in Oakland were more likely to have health insurance, a result of California expanding Medicaid coverage under the Affordable Care Act in 2014. Despite this, three-quarters of all women had attended at least one health care visit by appointment in the past year. In addition, over half had sought care at a hospital Emergency Department (Table 1).

\section{Health Care Since COVID-19}

Nearly half of women reported having medical appointments postponed or cancelled due to the COVID outbreak. However, many women also reported receiving health care by telemedicine (Table 2). The odds of having an appointment cancelled or postponed was significantly higher among Black women, after controlling for location, age and health insurance (Table 3). However, Black women also had higher odds of having a telemedicine appointment as a consequence of the outbreak. We found no differences by geographical region in COVID-related impacts on scheduled health care, once we controlled for race, age and health insurance (data not shown). Sixty (17\%) of the women had been tested for COVID over the data collection period (April-June 2020), a timeframe in which testing resources were scarce. Two women reported a positive result. Testing was more common in Oakland, where $23 \%$ of women were tested, compared

Table 1: Participant characteristics and health care by racial group.

\begin{tabular}{|c|c|c|c|c|c|}
\hline & All & Black & White & Other POC & \multirow{3}{*}{ p. } \\
\hline & $(\mathrm{N}=344)$ & $(n=205)$ & $(n=98)$ & $(n=41)$ & \\
\hline & $n(\%)$ & $n(\%)$ & $n(\%)$ & $n(\%)$ & \\
\hline Oakland & $181(52.8)$ & $146(71.2)$ & $16(16.3)$ & $19(47.5)$ & \multirow{3}{*}{0.001} \\
\hline Birmingham & $93(27.1)$ & $35(17.1)$ & $53(54.1)$ & $5(12.5)$ & \\
\hline Kansas City & $69(20.1)$ & $24(11.7)$ & $29(29.6)$ & $16(40.0)$ & \\
\hline \begin{tabular}{|l|} 
Ever incarcerated \\
\end{tabular} & $332(96.5)$ & $197(97.0)$ & $94(96.9)$ & $41(100.0)$ & 0.530 \\
\hline Ever probation or parole & $315(91.6)$ & $183(90.2)$ & $92(93.9)$ & $40(97.6)$ & 0.205 \\
\hline Has health insurance & $251(73.0)$ & $177(86.8)$ & $42(43.3)$ & $32(78.1)$ & 0.001 \\
\hline Health care by appointment past year & $263(76.5)$ & $173(84.4)$ & $59(60.2)$ & $31(75.6)$ & 0.001 \\
\hline Medical appointment cancelled or postponed due to COVID-19 & $146(42.4)$ & $104(50.7)$ & $30(30.6)$ & $12(29.3)$ & 0.001 \\
\hline Medical care by tele-medicine due to COVID-19 & $152(44.2)$ & $108(52.7)$ & $30(30.6)$ & $14(34.2)$ & 0.001 \\
\hline Tested for COVID-19 & $66(19.2)$ & $44(21)$ & $12(12)$ & $4(10)$ & 0.054 \\
\hline
\end{tabular}


Jennifer Lorvick (2020) Sources of Information and Health Care Experiences Related to COVID-19 among Women Involved in Criminal Legal System in Three U.S. Cities

Table 2: Most trusted source of information about COVID-19 by racial/ethnic group.

\begin{tabular}{|c|c|c|c|c|c|}
\hline & All & Black & White & Other POC & \multirow{3}{*}{ p. } \\
\hline & $(\mathrm{N}=344)$ & $(\mathrm{n}=205)$ & $(\mathrm{n}=98)$ & $(n=41)$ & \\
\hline & $n(\%)$ & $n(\%)$ & $n(\%)$ & $n(\%)$ & \\
\hline Television news & $147(42.7)$ & $104(50.7)$ & $31(31.6)$ & $12(29.3)$ & 0.001 \\
\hline Social media or websites & $35(10.2)$ & $17(8.3)$ & $10(10.2)$ & $8(19.5)$ & 0.095 \\
\hline Friends/family & $18(5.2)$ & $8(3.9)$ & $7(7.1)$ & $3(7.3)$ & 0.404 \\
\hline Government/social service agency & $30(8.7)$ & $8(3.9)$ & $17(17.4)$ & $5(12.2)$ & 0.001 \\
\hline Medical provider & $44(12.8)$ & $21(10.2)$ & $16(16.3)$ & $7(17.1)$ & 0.227 \\
\hline Other & $17(4.9)$ & $10(4.9)$ & $5(5.1)$ & $2(4.9)$ & 0.996 \\
\hline Don't trust any source & $52(15.1)$ & $36(17.6)$ & $12(2.2)$ & $4(9.8)$ & 0.286 \\
\hline
\end{tabular}

Table 3: Logistic regression of COVID-19 related health care experiences by race/ethnicity.

\begin{tabular}{|c|c|c|c|c|c|c|}
\hline & \multicolumn{2}{|c|}{ Model 1} & \multicolumn{2}{|c|}{ Model 2} & \multicolumn{2}{|c|}{ Model 3} \\
\hline & \multicolumn{2}{|c|}{ Care cancelled/postponed } & \multicolumn{2}{|c|}{ Telemedicine visit } & \multicolumn{2}{|c|}{ Tested for COVID-19 } \\
\hline & $\mathrm{AOR}^{\star}(95 \% \mathrm{CI})$ & p. & $\mathrm{AOR}^{\star}(95 \% \mathrm{CI})$ & p. & $\operatorname{AOR}^{\star *}(95 \% \mathrm{CI})$ & p. \\
\hline \multicolumn{7}{|l|}{ Race/ethnicity } \\
\hline African American & Referent & & Ref & & Ref & \\
\hline White & $0.53(0.29-0.98)$ & 0.045 & $0.50(0.27-0.92)$ & 0.027 & $0.85(0.37-1.94)$ & 0.698 \\
\hline Other POC & $0.43(0.20,0.93)$ & 0.033 & $0.56(0.27-1.19)$ & 0.131 & $0.54(0.18-1.66)$ & 0.181 \\
\hline
\end{tabular}

*Adjusted for study site, insurance status and had $1>$ medical appointment past year.

${ }^{*}$ Adjusted for study site, age and insurance status.

to $13 \%$ in Kansas City and $11 \%$ in Birmingham $(\mathrm{p}=0.027)$. Perceived susceptibility to COVID-19 was low overall: on a scale of 1 (not at all likely) to 10 (extremely likely), the mean score was 3.7 [SD 2.8]. Women in Oakland rated their susceptibility slighter higher (4.1) than women in Kansas City (3.2) or Birmingham (3.6) ( $\mathrm{p}=0.041)$. There were no significant racial/ethnic differences in perceived susceptibility (data not shown).

\section{Sources of Information about COVID-19}

Most women reported multiple sources of information about COVID-19, with a mean of 2.4 [SD 1.1]. Television news was the most frequently cited source of information regarding COVID-19 (83\%), followed by social media/websites (61\%) and friends/family (43\%). Other sources of information included government or social service agencies (21\%), medical providers (19\%) and radio (6\%). When asked to identify their single most trusted source of information, over half of women chose television news (Table 2). While many women endorsed friends and family as a source of information, very few (5\%) cited them as their most trusted source. Similarly, a relatively small proportion of women (13\%) said medical providers were their most trusted source of information about COVID-19. Black women had higher odds of choosing TV as the most trusted source than the other groups of women, after controlling for age and study site (Table 4). White women had higher odds of citing government or social service agencies as their most trusted source of information (Table 4). It is noteworthy that fifteen percent of women said they did not trust any source of information about COVID-19. This was higher among Black women but did not reach statistical significance in regression controlling for age and site. We found no significant regional differences in information sources or most trusted sources once controlling for race and age in regression analysis (data not shown).

Table 4: Logistic regression models of most trusted source of COVID-19 information by race/ethnicity.

\begin{tabular}{|c|c|c|c|c|c|c|}
\hline & \multicolumn{2}{|c|}{ Model 1} & \multicolumn{2}{|c|}{ Model 2} & \multicolumn{2}{|c|}{ Model 3} \\
\hline & \multicolumn{2}{|c|}{ Television News } & \multicolumn{2}{|c|}{ Web/social media } & \multicolumn{2}{|c|}{ Gov't/social service } \\
\hline & $\operatorname{AOR}^{*}(95 \% \mathrm{CI})$ & p. & $\operatorname{AOR}^{*}(95 \% \mathrm{CI})$ & p. & $\mathrm{AOR}^{*}(95 \% \mathrm{CI})$ & p. \\
\hline \multicolumn{7}{|l|}{ Race/ethnicity } \\
\hline African American & Referent & & Ref & & Ref & \\
\hline White & $0.33(0.18,0.59)$ & 0.001 & $1.61(0.62,4.21)$ & 0.328 & $7.48(2.61,21.38)$ & 0.001 \\
\hline Other POC & $0.39(0.18,0.85)$ & 0.018 & $2.91(1.10,7.69)$ & 0.031 & $2.90(0.79,10.64)$ & 0.108 \\
\hline
\end{tabular}

${ }^{*}$ Adjusted for study site and age. 


\section{Discussion}

Our examination of health care-related effects of COVID-19 among women with CL involvement found mixed results. While over $40 \%$ of women reported having health care appointments cancelled or postponed due to COVID-19, a roughly equal proportion received care by telemedicine, and there were no differences by region. This is consistent with a rapid uptick in telehealth visits for publicly insured people in urban areas throughout the U.S. in April-June 2020 [19]. The higher prevalence of COVID-19 testing in Oakland is likely a reflection of the more aggressive stance California took towards controlling infection, compared to the Midwest (Kansas/Missouri) and Southern (Alabama) states. Given this higher level of activity to address the pandemic, it is not surprising that the mean level of perceived susceptibility to COVID-19 was also higher among women Oakland, CA. Our findings regarding trusted sources of COVID-19 information did not vary by region; however, they revealed some interesting variations by race/ethnicity. Black women were significantly less likely than White women to choose government institutions or social services agencies as their most trusted source of information about the virus. In addition, very few Black women identified health care providers as their most trusted source. The long history of racism in government and criminal justice policies in the United States likely contributes to this mistrust [20,21], as does the legacy of unequal treatment and abuse in U.S. medicine $[20,22]$ Restorative work with communities of color is needed to address medical mistrust [23,24], particularly if a future vaccine is to be widely accepted among vulnerable groups [25]. Finally, it is striking that a notable proportion of women (15\%) said they didn't trust ANY source of information regarding COVID-19. This suggests an urgent need to investigate and implement innovative, non-traditional avenues for delivering public health information.

There are several substantial limitations to this study. While data were collected from women in different regions of the United States, the sample is not nationally representative of women involved in the CL system. Due to the exigencies of conducting data collection rapidly in the context of shelter-in-place orders, we were only able to reach threequarters of women in the parent study. It is possible those we were unable to reach were having different experiences; for example, it is possible that some were hospitalized with the virus. The potential of socially desirable response choices is always present with self-report data, although our questions didn't focus on typically stigmatized behaviors.

The COVID-19 pandemic has brought into sharp relief the underlying social drivers of poor health in the U.S., including racism, poverty and incarceration. In addition to affecting their health, these conditions affect the level of trust individuals put in social, medical and public health institutions. A U.S. national poll conducted in August 2020 found that, if a COVID-19 vaccine were made available, $45 \%$ of Black and $44 \%$ of Hispanic/Latinx people would not choose to be vaccinated, compared to $30 \%$ of Whites [26]. The need for accurate, trusted health communication to address this public health crisis is clear. It is incumbent on public health professionals to identify new, innovative avenues for public health messaging to vulnerable groups, and to improve the perceived trustworthiness of more traditional sources of information.

\section{Acknowledgements}

This research was supported by the U.S. National Cancer Institute (grant \#R01CA226838) and the U.S. National Institute of Minority Health and Health Disparities (grant \#R01MD010439). The authors thank the women who shared their experiences for the study, despite the disruption and uncertainty created by the COVID-19 pandemic.

\section{References}

1. Bronson J, Carson E (2019) Prisoners in 2017, Bureau of Justice Statistics, (eds.). Office of Justice Programs: Washington DC.

2. Zeng Z (2019) Jail Inmates in 2017 Bureau of Justice Statistics (eds.) Office of Justice Programs: Washington, DC.

3. Kaebele D, Alper M (2020) Probation and Parole in the United States, 2017-2018, Bureau of Justice Statistics (eds.) Office of Justice Programs: Washington DC.

4. Krieger N (2020) ENOUGH: COVID-19, Structural Racism, Police Brutality, Plutocracy, Climate Change - and Time for Health Justice, Democratic Governance, and an Equitable, Sustainable Future. American Journal of Public Health e1-e4. [crossref]

5. The Sentencing Project (2020) Fact Sheet: Incarcerated Women and Gils. Available from: https://www.sentencingproject.org/publications/incarcerated-women-andgirls/.

6. Binswanger IA, Krueger PM, Steiner JF (2009) Prevalence of chronic medical conditions among jail and prison inmates in the USA compared with the general population. J Epidemiol Community Health 63: 912-919.

7. Hawks L, Emily A Wang, Benjamin Howell, Steffie Woolhandler, David U Himmelstein, et al. (2020) Health Status and Health Care Utilization of US Adults Under Probation: 2015-2018. Am J Public Health 110: 1411-1417. [crossref]

8. Office of the Assistant Secretary for Planning and Evaluation (2020) Incarceration and Reentry. Available from: https://aspe.hhs.gov/incarceration-reentry.

9. Akiyama MJ, Spaulding AC, Rich JD (2020) Flattening the Curve for Incarcerated Populations - Covid-19 in Jails and Prisons. N Engl J Med 382: 2075-2077. [crossref]

10. Ramaswamy M, Jordana Hemberg, Alexandra Faust, Joi Wickliffe, Megan Comfort, et al. (2020) Criminal Justice-Involved Women Navigate COVID-19: Notes From the Field. Health Educ Behav 47: 544-548. [crossref]

11. Rozenfeld Y, et al. (2020) A model of disparities: risk factors associated with COVID-19 infection. Int J Equity Health 19: 126.

12. Millett GA, Austin T Jones, David Benkeser, Stefan Baral, Laina Mercer, et al. (2020) Assessing differential impacts of COVID-19 on black communities. Ann Epidemiol 47: 37-44. [crossref]

13. Poteat T, Gregorio A Millett, LaRon E Nelson, Chris Beyrer (2020) Understanding COVID-19 risks and vulnerabilities among black communities in America: the lethal force of syndemics. Ann Epidemiol 47: 1-3. [crossref]

14. Wadhera RK, Priya Wadhera, Prakriti Gaba, Jose F Figueroa, Karen E Joynt Maddox, et al. (2020) Variation in COVID-19 Hospitalizations and Deaths Across New York City Boroughs. JAMA 323: 2192-2195. [crossref]

15. Rodriguez-Diaz CE, Vincent Guilamo-Ramos, Leandro Mena, Eric Hall, Brian Honermann, et al. (2020) Risk for COVID-19 infection and death among Latinos in the United States: Examining heterogeneity in transmission dynamics. Ann Epidemiol. [crossref]

16. United States Bureau of Labor Statistics, Supplemental data measuring the effects of the coronavirus (COVID-19) pandemic on the labor market. 2020, United States Department of Labor: Washington DC.

17. Institute TA (2020) The COVID-19 Eviction Crisis: an Estimated 30-40 Million People in America Are at Risk. Available from: https://www.aspeninstitute.org/blogposts/the-covid-19-eviction-crisis-an-estimated-30-40-million-people-in-americaare-at-risk/

18. Centers for Disease Control and Prevention (2020) Coronavirus disease: Health equity considerations and racial and ethnic minority groups. Available from: https:// www.cdc.gov/coronavirus/2019-ncov/community/health 
19. ASPE (2020) Medicare beneficiary use of telehealth visits: Early data from the start of the COVID-19 pandemic, A.S.f.P.a. Evaluation, Editor. United States Department of Health and Human Services: Washington DC.

20. Spigner C (2007) Medical Apartheid: The dark history of medical experimentation on Black Americans from colonial times to the present. Journal of the National Medical Association 99: 1074. [crossref]

21. Binswanger IA, Nicole Redmond, John F Steiner, Leroi S Hicks (2012) Health disparities and the criminal justice system: an agenda for further research and action. J Urban Health 89: 98-107. [crossref]

22. Arnett MJ, Thorpe RJ, Gaskin DJ, Bowie JV, LaVeist TA (2016) Race, Medical Mistrust, and Segregation in Primary Care as Usual Source of Care: Findings from the Exploring Health Disparities in Integrated Communities Study. Journal of Urban Health: Bulletin of the New York Academy of Medicine 93: 456-467. [crossref]
23. Parsons S (2020) Addressing Racial Biases in Medicine: A Review of the Literature, Critique, and Recommendations. Int J Health Serv Pg no: 20731420940961. [crossref]

24. Sullivan LS (2020) Trust, Risk, and Race in American Medicine. Hastings Cent Rep 50: 18-26. [crossref]

25. Jamison AM, Quinn SC, Freimuth VS (2019) "You don't trust a government vaccine": Narratives of institutional trust and influenza vaccination among African American and white adults. Soc Sci Med 221: 87-94. [crossref]

26. Marist Institute for Public Opinion (2020) NPR/PBS NewsHour/Marist Poll Results: Election 2020, Trump, \& the Issues. Available from: http://maristpoll.marist.edu/ npr-pbs-newshour-marist-poll-results-election-2020-trump-the-issues/\#sthash. fm1RIlI9.dpbs.

\section{Citation:}

Lorvick J, Hemberg J, Cropsey K, Wickliffe J, Faust A, et al. (2020) Sources of Information and Health Care Experiences Related to COVID-19 among Women Involved in Criminal Legal System in Three U.S. Cities. ARCH Women Health Care Volume 3(5): 1-5. 